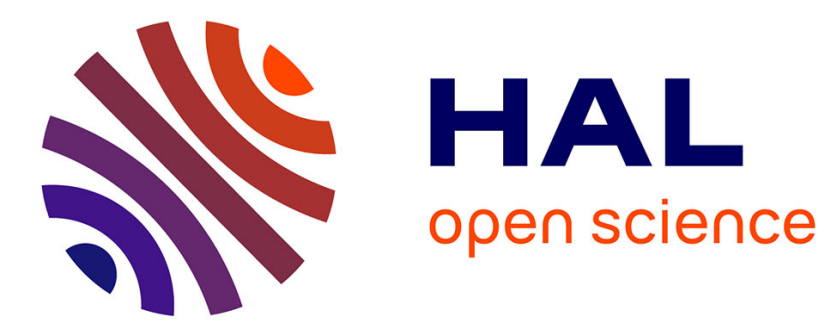

\title{
A Novel Metric for Determining the Constraining Effect of Resources in Manufacturing Simulation
}

\author{
Brian Patrick Kernan, Andrew Lynch, Con Sheahan, Dang Tung
}

\section{To cite this version:}

Brian Patrick Kernan, Andrew Lynch, Con Sheahan, Dang Tung. A Novel Metric for Determining the Constraining Effect of Resources in Manufacturing Simulation. International Journal of Production Research, 2010, pp.1. 10.1080/00207543.2010.481643 . hal-00605258

\section{HAL Id: hal-00605258 \\ https://hal.science/hal-00605258}

Submitted on 1 Jul 2011

HAL is a multi-disciplinary open access archive for the deposit and dissemination of scientific research documents, whether they are published or not. The documents may come from teaching and research institutions in France or abroad, or from public or private research centers.
L'archive ouverte pluridisciplinaire HAL, est destinée au dépôt et à la diffusion de documents scientifiques de niveau recherche, publiés ou non, émanant des établissements d'enseignement et de recherche français ou étrangers, des laboratoires publics ou privés. 


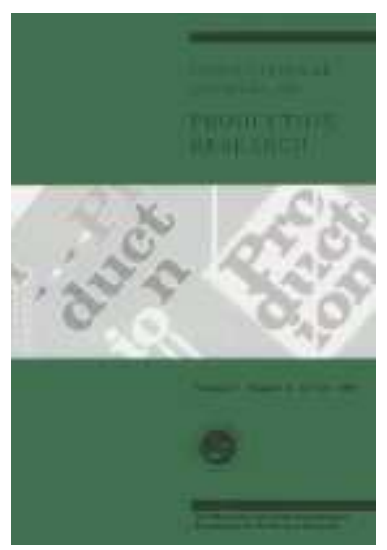

\section{A Novel Metric for Determining the Constraining Effect of Resources in Manufacturing Simulation}

\begin{tabular}{|r|l|}
\hline Journal: & International Journal of Production Research \\
\hline Manuscript ID: & TPRS-2009-IJPR-0748.R1 \\
\hline Manuscript Type: & Original Manuscript \\
\hline Complete List of Authors: & $\begin{array}{l}\text { Kernan, Brian; University Limerick, Enterprise Research Centre } \\
\text { Lynch, Andrew; University of Limerick, Enterprise Research Centre } \\
\text { Sheahan, Con; University of Limerick, Manufacturing and Operation } \\
\text { Department } \\
\text { Tung, Dang; University of Limerick, Manufacturing and Operation } \\
\text { Department }\end{array}$ \\
\hline Keywords: & SIMULATION, BENCHMARKING \\
\hline Keywords (user): & \\
\hline
\end{tabular}

\section{s ScholarONE" \\ Manuscript Central}




\title{
A Novel Metric for Determining the Constraining Effect of Resources in Manufacturing via Simulation
}

\author{
Brian Kernan, Andrew Lynch, Dang Tung, Con Sheahan \\ Manufacturing Operations \& Engineering, University of Limerick, Limerick, Ireland \\ Brian Kernan, Engineering Research Building, University of Limerick \\ Andrew Lynch, Engineering Research Building, University of Limerick \\ Dr. Dang Tung, Engineering Research Building, University of Limerick \\ Dr. Con Sheahan, Engineering Research Building, University of Limerick
}

This paper provides a novel method for determining the constraining effect of resources in a manufacturing system using discrete event simulation. Traditionally manufacturing systems are constrained by one or more bottlenecks. Eliminating or mitigating the bottleneck will speed up the system throughput. However, bottlenecking resources generally only refer to machines, and primarily focus on flow-shops not job-shops. One important resource we believe that is often overlooked is workers and their associated skills, and we propose that a particular skill could be flagged as a bottleneck resource. We define new metrics known as Resource Constraint Metrics (RCM) for measuring the constraining effect of a resource on the entire manufacturing system. These metrics are flexible and differentiate between the constraining effects of machines and their requested skills. The metrics can also deal with complex workflows with alternative routing, alternative resources, calendars (a necessary consideration when dealing with workers), worker performance, and multiple modes of operation of machines (e.g. run, setup, and maintenance). The use of RCMs in simulation aids in realworld decision-making, by determining which resource should be focussed on and improved to reduce the overall system constrainedness. This will have the effect of increasing throughput or at least providing the capacity for increased throughput.

Keywords: manufacturing, enterprise, resource, machine, skill, starvation 


\section{Introduction}

The work presented in this paper is founded primarily on the area of research of bottleneck detection in manufacturing simulation. There are numerous definitions as to what constitutes a bottleneck (Lawrence 1994). In Roser's paper (Roser 2002) a bottleneck is defined as a stage in a production system that has the largest effect on slowing down or stopping the entire system. Finding the bottleneck is no trivial task, and Cox and Spencer (Cox 1997) for example simply recommend that '...the best approach is often to go to the production floor and ask knowledgeable employees.' There are however a number of systematic methods available to locate the bottleneck for production systems however. One approach is to measure the utilisation of the different machines of the production system (Law 2000). The machine with the highest utilisation is considered to be the bottleneck. However, the utilisations of different machines are often very similar, so relatively long simulation run-times may be required to determine the system bottleneck with a high degree of confidence. Another frequently used method analyses the queue lengths of the machines in the production systems. In this method, either the queue length or the waiting time is determined, and the machine with the longest queue length or waiting time is considered to be the bottleneck. This method of detection is similar to looking at machine utilisation, since a machine with a large queue should also have commensurately high utilisation.

The shifting bottleneck method (Roser 2002) further distinguishes between a momentary bottleneck, describing the bottleneck at any given point in time, and an average bottleneck, describing the bottleneck behaviour over a selected period of time. The shifting bottleneck approach is based on the theory of constraints (Blackstone 2001) (Goldratt 1992). Although most manufacturing systems usually have one main bottleneck, in all but the simplest applications, bottlenecks are not static, but rather shift between different machines. These shifts may for example be due to the sequence of random events or due to a gradual change in the manufacturing system. A non-bottleneck machine may become a bottleneck, for example due to a machine failure, and similarly a bottleneck machine may become a non-bottleneck machine. Over longer periods of time, a system therefore may not only have one primary bottleneck, but also secondary and tertiary bottlenecks, i.e. machines which are also occasional bottlenecks, yet to a lesser extent that the primary bottleneck. This 
highlights the fact that it may be possible to improve throughput by not just focusing on the primary bottleneck. Roser (Roser 2002) deals with shifting bottleneck detection and uses an example with a job-shop arrangement with alternative routing, and alternative resources.

In Muthiah et al's paper (Muthiah 2007) the authors define a metric known as Overall Throughput Effectiveness (OTE) which builds upon the well established Overall Equipment Effectiveness (OEE), which is widely accepted as a primary performance metrics in manufacturing (Hansen 2002). While OTE has the benefits of monitoring total factory performance, being a useful aid in machine bottleneck detection in a varied selection of workflow sub-systems (e.g. machines in parallel, multiple routing) workers and skills were not considered during the development of the metric. Li et al. (Li 2009b) use analytical methods for bottleneck detection, based on historical data on machine blockages and starvations and also take into account machine failure times. The authors also note that using analytical methods for bottleneck detection are generally only appropriate for relatively simple workflows comprised of machines in sequence. However in Li's other paper (Li 2009a) an analytical data-driven method is used for bottleneck detection in a complex manufacturing system. Again however, workers are not dealt with in these two of Li et al's papers. For larger more complex systems, that include worker resources simulation would need to be used.

All of the aforementioned approaches for bottleneck detection generally assume heavily automated flow-shop production times where the human element can be ignored. However, in a large proportion of enterprises, workers are an important resource and cannot be disregarded when looking at bottleneck detection. The reason they tend to be ignored in simulation, is that they add an extra layer of complexity and they also necessitate the modelling of calendars, shifts, and breaks. Once workers are included in bottleneck analysis, it muddies the water and the conventional analyses may not suffice. Consider a simple production line with four machines and a single worker. Each machine has the same processing time and requires the worker to operate it. In this case the bottleneck resource is not any of the machines, but is in fact the worker. If we were to add a second worker, we will double the throughput. Another important issue which is not dealt with are machine modes of operation, such 
as setup, handling, and maintenance. Each mode may require a different set of skills to operate e.g. a technician may be required to perform maintenance on the machine, or a fitter and an electrician to setup the machine to process a new product type.

In our research, we have developed a database driven simulation model that is applicable to a generic manufacturing enterprise. All the necessary information about the enterprise such as resources, orders, workflows, and work calendars, is stored in a relational database (RDB), and a simulation engine, eM-Plant, instantiates a model of the enterprise from the database. The workflows we have developed are based on work by Russell et al. (Russell 2004) and Lin et al. (Lin 2009). Our workflows can deal with alternative routings such as OR-Splits and AND-Splits and the corresponding Joins, and also deals with alternative ranked resources. In addition the workflows can also contain subcontracting activities. On the resource level, machines can have multiple modes of operation such as setup and preventive maintenance, sequence dependent setup times, and workers can possess multiple skills, with an efficiency level being defined for each worker skill combination.

For the rest of this paper, in section 2 we define the metrics which we use to measure the contributing effect each resource has on the overall system constrainedness, and in section 3 we present some computational examples for calculating RCM values. Section 4 covers the determination of RCM values through a simulation of a real-life production plant. 


\section{Resource Constraint Metrics}

\subsection{Modelling Workers, Skills, and Efficiencies}

Firstly we define a machine as an internal locus where a manufacturing activity is performed. A machine can process orders as well as preventive maintenance requests (PMRs), and emergency maintenance requests (EMRs). A skill meanwhile, is a worker ability that is requested by a machine in its particular mode of operation. For example a lathe may require a skill 'Can operate Lathe' in its run mode of operation, and the skill 'Can repair Lathe' in its emergency maintenance mode of operation. A worker can have a set of skills, and each skill for a particular worker can have an efficiency between $0 \%$ and $100 \%$. A skill can be regarded as an abstract resource, and a worker can only provide one of their skills at a time. The efficiency increases the processing time for a machine as follows:

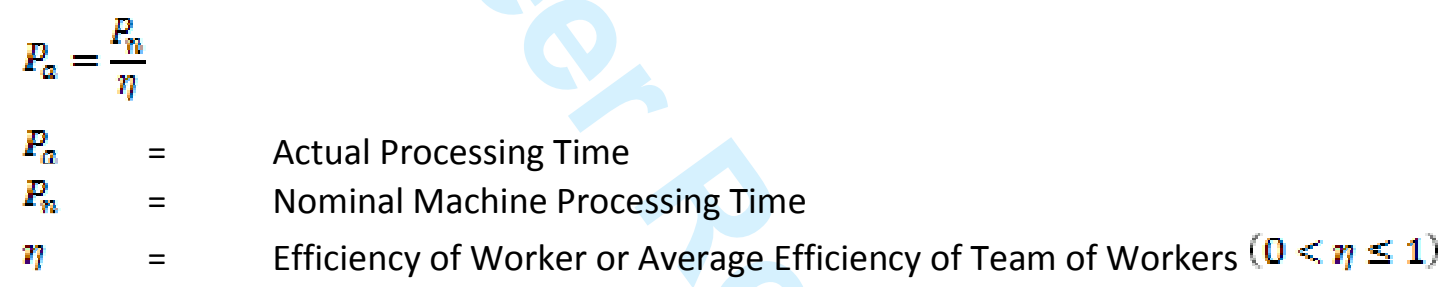

If the nominal processing time for a machine is 10 minutes, and if a worker with an efficiency of $75 \%$ is assigned to the machine, then the actual processing time will be 13.3 minutes. We must also define the concept of skill starvation. We say a machine is neglectfully starved for skill when capable workers are busy elsewhere on the shop-floor, and therefore unavailable to satisfy a request from the machine. Orders and PMRs may also be in queue for a machine that is suffering from absenteeism induced skill starvation, which means that there are no workers on the shop-floor for the current shift capable of operating the machine in either its standard modes of operation (run, setup, load, unload, teardown) or its relevant preventive maintenance mode. Our definition of starvation is not to be confused with the concept of a machine being starved for parts. In traditional simulation analysis, a machine that is idle and starved for parts is often frowned upon, and it is usually pointed out that its utilisation should be increased. However, since our simulator, models the entire enterprise, all parts/orders can be traced back to external customer demand. A machine that is idle is not necessarily a negative thing; if there is no 
associated customer demand there may be no point providing the machine with extra parts to produce (the exception being if the enterprise is building to stock). However, a machine that is starved for skill is impeding the movement of parts through the system, parts which will generally have actual associated customer demand.

\subsection{Formulae for Resource Constraint Metrics}

For each machine and skill the simulation model will calculate a value known as the Resource Constraint Metric (RCM) to quantify how much of a limiting factor that resource is to the manufacturing operations, and thus help identify it as a resource bottleneck. The higher the RCM value, the more of a limiting factor that resource is. Shown below are the actual formulae for calculating the RCMs for machines and skills.

\section{$\underline{\text { Machine RCM }}$}

$M_{i} M_{i=1}=\sum_{j=1}^{N}\left[\left(Q(p)_{i j}-Q(p(e))_{i j}\right)\right]$

\section{Skill RCM}

$$
\left.A_{k}\right\}_{k=1}^{S}=\sum_{i=1}^{M} \sum_{j=1}^{N}\left[\left(Q(s)_{i j k}+Q(p(e))_{i j k}\right)+H_{i j k}\right]
$$

\begin{tabular}{|c|c|c|}
\hline$M$ & $=$ & Total number of Machines \\
\hline S & $=$ & Total number of Skills \\
\hline $\mathrm{N}$ & $=$ & Total number of Orders, PMRs, and EMRs \\
\hline i & $=$ & Index for Machines $\left(\mathbf{M}_{\mathbf{i}}\right)$ \\
\hline j & $=$ & Index for Orders, PMRs, and EMRs $\left(\mathbf{R}_{\mathbf{j}}\right)$ \\
\hline k & $=$ & Index for Skills $\left(\mathbf{s}_{\mathrm{h}}\right)$ \\
\hline$Q(\mathbf{p})_{\text {i }}$ & $=$ & Queue time for $\mathbf{R}_{\mathbf{j}}$ at $\mathbf{M}_{\mathbf{i}}$ when $\mathbf{M}_{\mathbf{i}}$ was processing \\
\hline $\mathbf{Q}(\mathbf{p}(\mathbf{e}))_{\mathrm{i} 1}$ & $=$ & Queue time for $\mathbf{R}_{\mathbf{i}}$ at $\mathbf{M}_{\mathbf{i}}$ when $\mathbf{M}_{\mathbf{i}}$ was excess processing ${ }^{1}$ \\
\hline $\mathbf{Q}(\mathbf{p}(\mathbf{e}))_{\mathrm{i} \mid \mathrm{k}}$ & $=$ & Queue time for $\mathbf{R}_{\mathbf{i} \text { at }} \mathbf{M}_{\mathbf{i}}$ when $\mathbf{M}_{\mathbf{i}}$ was excess processing with $\mathbf{S}_{\mathbf{k}}$ \\
\hline$Q(s)_{i j k}$ & $=$ & Queue time ${ }^{2}$ for $\mathbf{R}_{\mathbf{i} \text { at }} \mathbf{M}_{\mathbf{i}}$ when $\mathbf{M}_{\mathbf{i}}$ was starved for $\mathbf{S}_{\mathbf{k}}$ \\
\hline
\end{tabular}

\footnotetext{
${ }^{1}$ Excess processing time that is incurred due to worker inefficiencies. See first paragraph on next page for a more detailed explanation.

${ }^{2}$ EMRs will never be in queue for a machine. When a machine fails, an EMR is generated and instantly replaces the order that was on the machine at the time of failure.
} 


\subsection{Explanation of Resource Constraint Metric Formulae}

Excess processing time is incurred due to worker inefficiency. This will only be relevant for machines that have workers assigned to them, and those workers have efficiency levels of less than $100 \%$ for a particular skill. For example, consider the nominal run-time for a machine is 10 minutes. If a worker with $80 \%$ efficiency for the requested skill by the machine is operating the machine, then the actual run-time will be 12.5 minutes. Other orders in queue will be waiting and thus contribute to the RCM, but for each order we add only 10 minutes for the RCM for the machine and add the other 2.5 minutes to the RCM for the skill. The 2.5 minutes is the excess processing.

We also separate out the different RCMs based on the shift when they were recorded. Separating out RCMs based on shift is useful in determining not only where the problem skill is, but when it is. For example, the main contributing factor to a high RCM for a particular skill could be due to a higher absenteeism rate during the night shift than the day shift. Sample RCMs are given in (Figure 1). We can see that we have a higher RCM value for skill 2 during the night shift than the day shift. Therefore, one possible recommendation to reduce the SCM is to increase the skill-set of a worker who works the night shift, by providing them with skill 2.

It should be pointed out that the equation on the previous page for calculating skill RCMs is applicable to multiple skill requests. For example a machine is neglectfully starved for skill for 10 minutes and is requesting 2 workers with skill A and the only two workers who possess this skill are on their lunch-break. If the machine has been assigned an order, and there are no other orders or PMRs in queue for the machine, then a value of 20 minutes will be appended to the RCM for that machine. If one worker had been idle and the other on their lunch-break, then the recorded value would be only 10 minutes. 
Another thing to note is that even though we model machine alternatives, an order can only ever be in queue for a single machine at any instant in time. When an order moves onto its next activity, and there are multiple machine alternatives, the order is moved to the queue which will result in it being processed fastest ${ }^{3}$. A simple analogy is a person in a supermarket; they look at their options in terms of check-outs, and they will choose the check-out which they believe will result in them leaving the supermarket quickest. It is possible for an order to switch to a queue for a different machine however. For example if a machine fails suddenly, the orders that were in queue for it may be moved over to a queue for an alternative machine, if the time to repair the first machine is expected to be longer than setting up the alternative machine.

The calculations do not attempt to weight orders based on priority, quantity, or cost. We do not weight by priority, since higher priority orders should spend proportionally less time in queue for machines, and on machines that are starved for skill than lower priority orders anyway. Also, we do not weight by quantity or cost, since the calculations also include maintenance requests; if we were to try and weight an order, we were have to apply some arbitrary weighting variable to maintenance requests. However, future work may dictate that it is necessary to weight each order by the total euro-cost associated with each order. In this way a high cost order will contribute proportionally more to the RCM for the constrained resource, than lower cost orders. The weighting variable for maintenance requests would be a euro-cost that captures the delay of a PMR in queue for a machine, or a starved machine that is processing a PMR or EMR. Assigning a weighting variable to maintenance requests is in the realm of fuzzy logic however; intuitively we can say that the RCM from a machine that fails unexpectedly and is waiting for a worker rated to repair it, should be worse that the RCM for a machine that is starved for skill while processing a low priority work order.

When we run a simulation each machine and skill will have a generated RCM value, which will generally have units of hours. We are only interested in relative

\footnotetext{
${ }^{3}$ This is a prediction within the simulation at run-time however, and may actually turn out to be wrong. For example if the selected machine fails unexpectedly, the alternative machine may have been a better choice.
} 


\subsection{Advantages of Resource Constraint Metrics}

The advantage of using RCMs over simply trying to locate the bottleneck machine, is that in any manufacturing systems which are other than the most simple cases, we need a way of ranking the contribution of each resource to the system constrainedness. The case of performing analysis on a manufacturing system and claiming that 'machine $\mathrm{X}$ is the bottleneck' will generally only be tenable for a single sequential production line, with no workers modelled. Roser's paper (Roser 2002) has expanded the research by creating a methodology to identifying secondary and tertiary bottlenecks, but the RCM is a more flexible way of quantifying (relatively) the contribution of each machine to the overall system constrainedness. Once we factor in workers and skills, which are often neglected in simulation, but a critical resource in most enterprises, we need a way to differentiate between the contributing effect of machines and workers. The RCMs do this in a intuitive manner, and can be used to aid in real-world decision-making. By looking at the status quo or as-is situation on the manufacturing shop-floor, the RCM values will inform the user where best to focus their efforts in order to reduce the overall system constrainedness e.g. add a new machine, reduce the processing time of an existing machine, add a new worker, or upskill an existing worker. This is particularly relevant for small enterprises with relatively small workforces, and where workers must be included as a resource in the simulation of the system; upskilling an existing worker could potentially have an equivalent rate-of-return as purchasing a new machine but without the capital investment. 
Subsequent simulations with the changes in place should support the RCM data i.e. we should see a reduction in SCM, and we may see a reduction in the number of late satisfied customer demands (a positive consequence of orders flowing through the system quicker). We may also see an increase in the finished goods inventory, since a decrease in SCM may result in reduced work order fulfilment lead time. It is important to note however, that a high RCM for a skill associated with a particular machine can be tackled by reducing the processing time for the machine. This is because by reducing the processing time, there is less opportunity and time for the machine to be starved for skill.

Another advantage of using these metrics is that the coding for the calculations is incorporated directly into a database driven general simulation model that has been developed in eM-Plant. Our approach instantiates a model of an enterprise from a RDB which results in significantly reduced build effort. Since the coding for calculating RCM is build into the simulation model in eM-Plant the coding for the metrics are not specific to a single case study. Multiple instances of enterprises can be represented in relational database format, and the RCM values calculated, once the model is automatically instantiated in eM-Plant. The common approach to building simulation models is to build them ad hoc; from the ground up, using components and elements in a simulation application user interface. For example the paper by Alfieri (Alfieri 2009) describes a relatively complex simulation of a cardboard company which contains elements such as multi-machine stations, sequence-dependent setup times, resource calendars, and external operations. Similarly the paper by Nacsa (Nacsa 2008) demonstrates a model that includes components such as machines, shifts, and workers. These models are however each specific to the shop-floor of a single manufacturing firm. In the case of the paper by Nacsa, the model was built using Siman, a simulation application.

Our simulator is capable of instantiating models from a database at least as complex as described in (Alfieri 2009) and (Nasca 2008) and will produce RCMs, and other decision oriented KPIs. The RCMs could therefore potentially be used for controlling resources on an operational level, in a similar manner to the paper by Li et al. (Li 2009c) where the authors have achieved real time production improvement through bottleneck control. 


\section{Computational Examples}

\subsection{Example One}

This section will describe three computational examples. The first example deals with a simple sequential workflow with four machines each with a constant processing time of one minute. We start the simulation with 200 orders in queue for the first machine, and we end the simulation when all the orders have left the system. At the end of the simulation we find the following RCM values as shown in (Table 1).

As expected, the only non-zero RCM value for the machines is for the first machine. Since the first machine feeds machine B at a rate of one order per minute, and machines $\mathrm{B}, \mathrm{C}, \mathrm{D}$ have a processing time of one minute, no orders will be in queue downstream of machine A. Also, in this simple example we are not dealing with workers, hence none of the machines will undergo skill starvation. The reason machine A has a non-zero RCM value is because at the start of the simulation there are 200 orders in queue for the machine. From the formula for RCM for machines, the RCM value for a machine is proportional to the queue size or WIP (work-inprocess) for the machine; the more parts in queue for a machine, the higher the RCM for the machine, and also for the skill associated with the machine if the machine undergoes skill starvation. The RCM for example one can be calculated by noting that at time 1, there will be 199 orders that have been in queue for machine 1 for 1 minute. Hence we add 199 minutes to the RCM for machine 1. At time 2, there will be 198 orders that have been in queue for machine 1 for 1 minute, so we add on 198 minutes to the RCM value. Therefore, the total RCM value at the end of the simulation should be given by:

$$
\sum_{i=1}^{n} i=\frac{n^{2}+n}{2}
$$

Which for a value of $n=199$ yields an RCM value of 19,900. The reason for the discrepancy between the calculated value of 19,900 and the simulated value of 
20,225 is due to a condition known as event time shifting in the simulation model, whereby events which are technically supposed to occur at the same time they were trigged, must be scheduled for 1 second in the future. Events must be dealt with in this manner in eM-Plant in order to avoid events being inadvertently bypassed by the simulator. However, the error in RCM values for this simple model is only approximately $1.6 \%$, and since the simulator is aimed at simulating enterprises over relatively long periods of time, this incurred error is negligible, and should not negatively affect the output results in a decision making context. Next, if we reduce the processing time of machine A to 30 seconds (New Scenario 1), we obtain the following results as shown in (Table 2).

Because machine A can process orders twice as fast as before, a queue builds up in front of machine B. Hence machine B will now have a non-zero RCM. As expected however, the SCM stays the same at 20,225 minutes. This indicates that halving the processing time of machine B has had no effect on the overall system constraint metric. Only if we reduce the processing time of all four machines will we notice a reduction in the SCM. Shown in (Table 3) are the results when the processing time of all the machines is 30 seconds (New Scenario 2). The value of 10,278 minutes is approximately half of 20,225 minutes; we have reduced the SCM by $50 \%$ which corresponds to a doubling of throughput.

\subsection{Example Two}

In the second example, we use the model from first example with some alternations. The processing times of all machines are now stochastic, uniformly distributed between 55 and 60 seconds, and orders are now released to the system at a rate of one order per minute. This will have the effect of reducing the queue in front of the first machine. Since the processing times are stochastic we run the simulation for 10 replications until all the orders have left the system. Shown in (Figure 2) are the RCM values obtained for this example.

For each machine, from the $\mathrm{X}$-axis to the thick black line in the middle of the grey box, the corresponding $\mathrm{Y}$ value is the mean RCM. From this value, to the top 
and bottom of the grey box, represents one standard deviation ${ }^{4}$ above and below the mean. We see that machine A has a zero RCM value. Since orders are now released at a rate of one per minute, and the longest processing time capable for the machine is one minute, there will never be orders in queue for machine A. The RCM values increase the further downstream we go. This is due to the cumulative effect of the variability of the processing times. Next if we change the processing time of machine $\mathrm{C}$ to a uniform distribution of between 80 and 85 seconds we obtain the following results for the RCMs, for 10 replications as shown in (Figure 3).

We see that machine $\mathrm{C}$ dominates. Again this is to be expected since it is now the bottleneck because it has the longest processing time of the four machines, and thus will have the largest queue in front of it. Machine B has a non-zero RCM but it is dwarfed by the RCM for machine C. The RCM value for machine $\mathrm{D}$ is now zero, since machine $\mathrm{C}$ will release orders at a rate of less than one per minute, and since the processing time of machine $\mathrm{D}$ will never exceed one minute, there will never by any orders in queue for machine D. If we want to make improvements to the system, we should concentrate on machine C. Also it is worth noting that the RCM value for machine D in (Figure 3) is 130 hours, whereas when all the machines had the same processing time, the highest RCM value for machine D is around 0.015 hours (54 seconds) (Figure 2). There is a significant difference in scale.

\subsection{Example Three}

In the third example we introduce workers and skills, job dependent processing times, and multiple workflows. We have three sequential workflows in total

- Workflow $1=\{$ Activity $\mathrm{A} \rightarrow$ Activity $\mathrm{B} \rightarrow$ Activity $\mathrm{C} \rightarrow$ Activity $\mathrm{D}$ \}

- Workflow $2=\{$ Activity $\mathrm{B} \rightarrow$ Activity $\mathrm{A} \rightarrow$ Activity $\mathrm{D} \rightarrow$ Activity $\mathrm{C}\}$

- Workflow $3=$ Activity $\mathrm{C} \rightarrow$ Activity $\mathrm{B} \rightarrow$ Activity $\mathrm{A} \rightarrow$ Activity $\mathrm{D}\}$

Activities are performed at machines as follows:

- Activity A

- Activity B

- Activity C performed at performed at performed at
\{Machine A\}

$\{$ Machine B

$\{$ Machine C $\}$

\footnotetext{
${ }^{4}$ We use sample standard deviation, with Bessel's correction for measuring the spread of the results, which we store in a separate RDB. We do not use confidence intervals, since confidence intervals assume that the outputted results follow the normal model distribution which may not be the case.
} 
- Activity D performed at $\quad\{$ Machine D

We assume machines only have a single mode of operation "Run" and machines request the following skills for their "Run" mode of operation. Also each machine sorts jobs in the queue by their priority, and then by shortest processing time.

- Machine A : Run requests skills $\quad\{$ Skill A $\}$

- Machine B : Run requests skills $\quad\{$ Skill B $\}$

- Machine C : Run requests skills $\quad\{$ Skill C $\}$

- Machine D : Run requests skills $\quad\{$ Skill D $\}$

We have three workers with the following skill-set:

- Andrew

- Brian

- Con has skills

has skills

has skills
$\{$ Skill A $\}$

$\{$ Skill B $\}$

\{Skill C, Skill D\}

Processing times are dependent on job ID and we have 6 jobs in total. The processing times have units of minutes and are given in (Table 4). The information on jobs is shown in (Table 5). Each job is given the same arbitrary scheduled release date, which corresponds to time zero in the simulation model, and the same internal due date. The priority of an order dictates its queuing priority and worker dispatching priority i.e. a high priority order will be given higher preference to be processed ahead of a lower priority order.

An overview of the relationships between workflows and skills is given for workflow 1 in (Figure 4). The linkage type between activities is 'sequence', and simply defines a precedence constraint dependency between activities i.e. we can not start activity B until activity A is completed. Looking at this diagram, we see that Con will need to share his time between machines C and D. Therefore there is a potential for these two machines to be starved for skill.

We run the simulation for a simulated time of 45 minutes, after which all the jobs have been processed. Shown in (Figure 5) is a Gantt chart for the machines. We use a different colour to denote each job, and when a job is on a machine that is starved for skill, we use a thin binary colour strip with the same colour as the job plus the colour red. This Gantt chart does not try to represent jobs which are queued for machines. For example, job 5 (yellow) between time 20min and $25 \mathrm{~min}$ is in queue 
for machine $\mathrm{D}$, but during this time period machine $\mathrm{D}$ is busy processing job 4 (grey); job 5 is not shown in the Gantt chart for this period. Also, machine $\mathrm{C}$ starts processing job 4 ahead of job 6 because job 4 is higher priority than job 6. Machine A processes job 1, job 5, and job 3 in that order because they have increasing processing times. If we look at machine $\mathrm{C}$ at time 14 we see that job 5 is loaded onto the machine, but the only worker capable of operating machine $\mathrm{C}$ is $\mathrm{Con}$ and he is currently busy with job 2 on machine $\mathrm{D}$. Therefore machine $\mathrm{C}$ is neglectfully starved for skill $\mathrm{C}$ for two minutes. When Con finishes job 2 he moves up to machine $\mathrm{C}$ and begins processing job 5. Also, as expected at any instant in time, machines C and D will never be simultaneously processing. The worker Andrew only possess skill A, and since machine $\mathrm{A}$ is the only machine that requests this skill, Andrew is confined to machine A. This implies that it is impossible, under the current conditions, for machine A to be starved for skill. It is the same situation with the worker Brian and machine B. Shown in (Figure 6) is a Gantt chart for the jobs. We use a different colour to denote each machine, and when a machine is starved for skill, we use a thin binary colour strip with the same colour as the machine plus the colour red.

We will now show how we calculate the RCM values for machine D and skill $\mathrm{D}$ which are values of 17 minutes and 10 minutes respectively. In (Table 6) the second column $Q_{D}$ contains, for each job, the total time the job spent in queue for machine D. The third and fourth columns break this time down, for each job, into the time when machine D was processing, and when machine D was starved for skill (skill D in this case). For example, looking at (Figure 6) for job 6 we see that it spent a total of 11 minutes in queue for machine D. However, for 3 of these 11 minutes machine D was starved for skill D when processing job 5. So this 11 minutes is separated out to 8 minute for $Q(p)_{D}$ and 3 minutes for $Q(p)_{D D}$. In the fifth and final column, we record the time for each job, when the job was on machine D and the machine was starved for skill D.

$Q_{D} \quad=\quad$ Total Time job in queue for $\mathrm{M}_{D}$

$Q(p)_{D}=$ Time job in queue for $\mathrm{M}_{D}$ when $\mathrm{M}_{\mathrm{D}}$ is processing

$Q(s)_{D D}=\quad$ Time job in queue for $M_{D}$ when $M_{D}$ is starved for $S_{D}$

$H_{D D}=$ Time when $M_{D}$ was neglectfully starved for $S_{D}$ 
When we sum up the third column in (Table 6) we get a value of 17 minutes which is the RCM value for machine D. When we sum up the fourth and fifth columns we get 3 minutes and 7 minutes respectively, and when we add these together we get a value of 10 minutes which is the RCM for skill D. We do not have to consider the other machines in the calculation of the RCM for skill D since they will never be starved for this skill.

dShown in (Figure 7) are the RCMs for all the machines and skills. Looking at this graph, some recommendations could be giving skill $\mathrm{C}$ or skill $\mathrm{D}$ to the workers Andrew or Brian, or reducing the processing time of machine B. These changes could reduce the SCM and also reduce the makespan of the jobs i.e. the time when the last job leaves the system. However, it should be pointed out that our model here is relatively simple, and over a very short period of time. Decisions made based on RCM values should be for real world systems that are in steady state and over relatively long periods of time. In this way we can be confident in the relativity of RCM values and the dominance of the constraining power of one resource over another on the shop-floor.

\section{Real Life Example}

In this section we use the simulation model to determine the RCM values for an entire factory. The factory under examination is a SchuF Fetterolf production plant in Ireland that designs and manufactures industrial valves that control, isolate, divert, or sample gases, liquids, slurries, or powders. The main characteristics of the plant being simulated are as follows:

- Simulation time of one year

- 1,600 Work Order / Purchase Order Lines

- 470 Sales Order Lines

- 1,700 Precedence Constraints amongst Orders

- 2,500 Products / Components

- 24 Workers

- 11 Skills

- 18 Machines

- 8 Vendors / Subcontractors

- 150 Workflows 
- One 8 hour shift, five day working week

- Multiple Routing, Alternative Resources

- Multiple Machine Modes of Operation

- 1,000 Different Processing Times associated with different workflows and different machines

This information was stored in the companies ERP (Enterprise Requirements Planning) system and was translated and stored in the Relational Database for the simulation model. The primary source of variability being modelled is worker absenteeism and tardiness. Based on the following papers (Barmby 1991), (Bytestart 2008), (Irish Times 2008) we assume the following parameters:

- Probability of being absent is $3.3 \%$

- Probability of being late is $4.4 \%$ (However, $65 \%$ probability that when a worker is late this will occur on a Monday)

- Average Lateness is 10 minutes, with an upper limit of 18 minutes. Hence, assume actual lateness time is log-normally distributed with mean 10 minutes and standard deviation 2 minutes, where probability of being more than 18 minutes late is less than $5 \%$.

The main caveat with modelling absenteeism and tardiness in this manner is that we assume all workers have an equal probability of missing a day of work, or being late for work. In reality of course, some workers will be more prone to missing work than others. A more accurate way to model this variability is to look at historical data for each worker and assign a probability for each worker. However, this data was not currently available at the time this paper was written. It should be noted that with a probability of being absent of $3.3 \%$ and with 24 workers the chances of at least one worker being absent on a given day is greater than $55 \%$.

Another source of variability in the model is that equally ranked alternative resources are randomly selected. For example, if a machine requires a worker with the skill 'Can Setup' and two equally ranked workers possess this skill, then one of the workers will be selected at random. The same rule applies to alternative machines for a particular activity. We run the simulation for ten replications, once with worker 
absenteeism and worker tardiness being modelled, and for another ten replications with absenteeism and tardiness switched off.

We test for a statistically significant difference (with a significance level of 5\%) between the mean total skill RCM for the two different experiments using R, a statistical analysis software package. Firstly we perform a Kolmogorov-Smirnov test on both sets of data to see if there is sufficient evidence that the data deviates from the normal model. We get $\mathrm{p}$-values greater than 5\% meaning we can assume the data is normally distributed. Next we check the data sets to see if we can assume equal variances. In this case we get a p-value less than 5\% indicating that the variances are unequal. This result was to be expected since the lions-share of variance is from modelling absenteeism and this is only present in the first experiment. The only source of variance present in the second experiment is from the random selection of equally ranked alternative resources. Finally we perform a Welch test for testing for significance difference between means with unequal variances and we get a p-value less than 5\% indicating that the means are not equal. This is evident from Figure 8. This means that when we eliminate worker absenteeism and tardiness this translates to a $79 \%$ reduction in skill RCM.

When we perform a similar statistical analysis on the total machine RCM we find that there is no evidence of a significance difference in means of total machine RCM between the two experiments, and this can be seen in Figure 9. This result was to be expected since eliminating worker absenteeism and tardiness should not significantly reduce the machine RCMs. If instead the experiments were only looking at the effect of machine break-downs, which can be regarded as the machine equivalent of worker absenteeism, then we should find a significant difference between machine RCMs and a possible significant difference between skill RCMs. Machine RCMs and skill RCMs in this context would be dependent on the mean time to repair the machine (MTTR), and the availability of skills to repair the machine.

When we look at the System Constraint Metric (SCM) which is simply the sum of skill RCMs and machine RCMs we see that machines are the main contributor to SCM (See Figure 10.). The final result is that based on our simulation model of the SchuF plant, when we eliminate worker absenteeism and tardiness the SCM reduces 
significantly by an average of $4.1 \%$. Further work would involve analysing historical data and obtaining absenteeism and tardiness percentages based on each worker. Analysis of the different skill RCMs could also inform us which skills are critical, and simulation could also inform us the effect of absenteeism from different workers on the system constrainedness.

\section{Summary}

The metrics presented in the paper are an intuitive and highly flexible way of determining the constraining power of a resource in a manufacturing system, via simulation. They are superior to traditional bottle neck detection methods by taking into account, many aspects of a manufacturing that are usually ignored in simulation models, such as workers, calendars, multiple modes of machine operation, and complex workflows. Resource constrains metrics are a way of quantifying the constraining power of worker-skills as well as machines, and can aid in real-world decision making, by determining which resource should be focussed on and improved, in order to reduce the overall system constrainedness. This will have the effect of increasing throughput or at least providing the capacity for increased throughput. Additionally it can result in improved customer demand satisfaction, since reduced system impedance can mean a commensurate reduction in the number of incidents where a customer's sales order is satisfied late. Further work using these metrics and one that the authors are currently working on is using these metrics to identify the most constrained skill, and simulating worker trainer, and how this improves the economic performance of the organisation e.g. upskilling worker Andrew with Skill B with yield the best economic performance compared with all other worker-skill training combinations. 


\section{References}

Alfieri, A. (2009). "Workload simulation and optimisation in multi-criteria hybrid flowshop scheduling: a case study." International Journal of Production Research Vol. 47, 18, 5129-5145.

Barmby, T., Orme, C., Treble, J. (1991). "Worker Absenteeism: An Analysis Using Microdata." The Economic Journal Vol. 101, 405, 214-229

Blackstone, J. H. (2001). "Theory of Constraints - A Status Report." International Journal of Production Research Vol. 39, 6, 1053-1080

Bytestart (2009, December 20). "Worker lateness costs business $£ 66$ million every year", bytestart.co.uk - The Small Business Portal

Cox, J., Spencer, M. (1997). "The Constraints Management Handbook", Boca Raton, Florida, St Lucie, Press

Goldratt, E. M. (1993). "The Goal: A Process of Ongoing Improvement", New York, North River Press, Inc.

Hansen, R. C. (2002). "Overall Equipment Effectiveness - A Powerful Production/Maintenance Tool for Increased Profits". New York, NY, Industrial Press.

Irish Times (2008, September 2) "Absenteeism Issues", IrishTimes.com

Law, A., Kelton, D. (2000). "Simulation Modeling \& Analysis", McGraw Hill.

Lawrence, S., Buss, A. (1994). "Shifting Production Bottlenecks: Causes, Cures, and Conundrums." Journal of Production and Operations Management Vol. 3, 1, 1059-1478

Li, L. (2009a). "Bottleneck Detection of complex manufacturing systems using a data-driven method" International Journal of Production Research Vol. 47, 24, 6929-6940.

Li, L., Chang, Q., Ni, J. (2009b). "Data Driven Bottleneck Detection of Manufacturing Systems." International Journal of Production Research Vol. 47, 20, 5019-5036.

Li, L., Chang, Q., Ni, J. (2009c). "Real time production improvement through bottleneck control " International Journal of Production Research Vol. 47, 21, 6145-6158.

Lin, H., Fan, Y., Newman, S. (2009). "Manufacturing Process Analysis with Support of Workflow Modelling and Simulation " International Journal of Production Research Vol. 47, 18, 5129-5145.

Muthiah, K., Huang, S. (2007). "Overall throughput effectiveness (OTE) metric for factory-level performance monitoring and bottleneck detection." International Journal of Production Research Vol. 45, 20, 4753-4769

Nacsa, J. (2008). "SIMAN Simulation of Assembly Operations in a Furniture Company."

Roser, C., Nakano, M., Tanaka, M. (2002). "Shifting Bottleneck Detection". Winter Simulation Conference, Orlando, Florida 
Russell, N., Van Der Aalst, W. (2004). "Workflow Resource Patterns: Identification, Representation and Tool Support", Eindhoven University of Technology.

\begin{tabular}{|ll|}
\hline Machine & Resource Constraint Metric / Minutes \\
\hline Machine A & 20225 \\
\hline Machine B & 0 \\
\hline Machine C & 0 \\
\hline Machine D & 0 \\
\hline SYSTEM & 20225 \\
\hline
\end{tabular}

Table 1. RCMs for Computational Example 1 (Baseline)

\begin{tabular}{|ll|}
\hline Machine & Resource Constraint Metric / Minutes \\
\hline Machine A & 10278 \\
\hline Machine B & 9947 \\
\hline Machine C & 0 \\
\hline Machine D & 0 \\
\hline SYSTEM & $\mathbf{2 0 2 2 5}$ \\
\hline
\end{tabular}

Table 2. RCMs for Computational Example 1 (New Scenario 1)

\begin{tabular}{|ll|}
\hline Machine & Resource Constraint Metric / Minutes \\
\hline Machine A & 10278 \\
\hline Machine B & 0 \\
\hline Machine C & 0 \\
\hline Machine D & 0 \\
\hline SYSTEM & $\mathbf{1 0 2 7 8}$ \\
\hline
\end{tabular}

Table 3. RCMs for Computational Example 1 (New Scenario 2)

\begin{tabular}{|lcccc|}
\hline & Machine A & Machine B & Machine C & Machine D \\
\hline Job 1 & 1 & 4 & 4 & 1 \\
\hline Job 2 & 6 & 3 & 3 & 2 \\
\hline Job 3 & 5 & 5 & 2 & 3 \\
\hline Job 4 & 4 & 5 & 5 & 5 \\
\hline Job 5 & 2 & 2 & 4 & 4 \\
\hline Job 6 & 3 & 4 & 3 & 4 \\
\hline
\end{tabular}

Table 4. Processing Times (in Minutes) for Computational Example 3

\begin{tabular}{|llllll|}
\hline Job ID & $\begin{array}{l}\text { Assigned } \\
\text { Workflow }\end{array}$ & Priority & $\begin{array}{l}\text { Scheduled } \\
\text { Release Date }\end{array}$ & $\begin{array}{l}\text { Internal } \\
\text { Due Date }\end{array}$ & Status \\
\hline Job 1 & Workflow 1 & Low & $01 / 01 / 08$ & $02 / 01 / 08$ & Unreleased \\
\hline
\end{tabular}




\begin{tabular}{|llllll|}
\hline Job 2 & Workflow 2 & Normal & $01 / 01 / 08$ & $02 / 01 / 08$ & Unreleased \\
\hline Job 3 & Workflow 1 & Low & $01 / 01 / 08$ & $02 / 01 / 08$ & Unreleased \\
\hline Job 4 & Workflow 3 & Normal & $01 / 01 / 08$ & $02 / 01 / 08$ & Unreleased \\
\hline Job 5 & Workflow 1 & Low & $01 / 01 / 08$ & $02 / 01 / 08$ & Unreleased \\
\hline Job 6 & Workflow 3 & Low & $01 / 01 / 08$ & $02 / 01 / 08$ & Unreleased \\
\hline
\end{tabular}

Table 5. Jobs for Computational Example 3

\begin{tabular}{|lcccc|}
\hline Job ID & $\mathbf{Q}_{\mathrm{D}}$ & $\mathbf{Q}(\mathbf{p})_{\mathrm{D}}$ & $\mathbf{Q}(\mathbf{s})_{\mathrm{DD}}$ & $\mathrm{H}_{\mathrm{DD}}$ \\
\hline Job 1 & 0 & 0 & 0 & 0 \\
\hline Job 2 & 0 & 0 & 0 & 0 \\
\hline Job 3 & 4 & 4 & 0 & 0 \\
\hline Job 4 & 0 & 0 & 0 & 2 \\
\hline Job 5 & 5 & 5 & 0 & 3 \\
\hline Job 6 & 11 & 8 & 3 & 2 \\
\hline TOTAL & $\mathbf{2 0}$ & $\mathbf{1 7}$ & $\mathbf{3}$ & $\mathbf{7}$ \\
\hline
\end{tabular}

Table 6. Breakdown of Queue/Starvation Time for Computational Example 3

\begin{tabular}{|l|c|c|c|c|c|c|c|c|c|c|}
\hline & \multicolumn{10}{|c|}{ Replication Number } \\
\cline { 2 - 12 } & $\mathbf{1}$ & $\mathbf{2}$ & $\mathbf{3}$ & $\mathbf{4}$ & $\mathbf{5}$ & $\mathbf{6}$ & $\mathbf{7}$ & $\mathbf{8}$ & $\mathbf{9}$ & $\mathbf{1 0}$ \\
\hline Skill RCM (Hours) & 64 & 61 & 37 & 25 & 52 & 39 & 12 & 15 & 15 & 30 \\
\hline Machine RCM (Hours) & 592 & 592 & 591 & 598 & 591 & 592 & 592 & 598 & 588 & 583 \\
\hline SCM (Hours) & 656 & 653 & 628 & 623 & 643 & 631 & 604 & 613 & 603 & 613 \\
\hline
\end{tabular}

Table 7. Simulation Results for Production Plant with Absenteeism and Tardiness

\begin{tabular}{|l|c|c|c|c|c|c|c|c|c|c|}
\hline & \multicolumn{10}{|c|}{ Replication Number } \\
\cline { 2 - 12 } & $\mathbf{1}$ & $\mathbf{2}$ & $\mathbf{3}$ & $\mathbf{4}$ & $\mathbf{5}$ & $\mathbf{6}$ & $\mathbf{7}$ & $\mathbf{8}$ & $\mathbf{9}$ & $\mathbf{1 0}$ \\
\hline Skill RCM (Hours) & 5 & 6 & 8 & 10 & 6 & $\mathbf{7}$ & 7 & 11 & 7 & 7 \\
\hline Machine RCM (Hours) & 594 & 595 & 596 & 588 & 600 & 594 & 593 & 587 & 595 & 595 \\
\hline SCM (Hours) & 599 & 601 & 604 & 599 & 606 & 602 & 601 & 598 & 603 & 602 \\
\hline
\end{tabular}

Table 8. Simulation Results for Production Plant with no Absenteeism and Tardiness

Figure 1. Sample Resource Constraint Metrics (By Shift)

Figure 2. Resource Constraint Metrics for Computational Example 2 (Baseline)

Figure 3. RCMs for Computational Example 2 (New Scenario 1)

Figure 4. Breakdown of Workflow 1 for Computational Example 3

Figure 5. Machine Gantt Chart for Computational Example 3

Figure 6. Job Gantt Chart for Computational Example 3

Figure 7. Resource Constraint Metrics for Computational Example 3

Figure 8. Skill RCMs for Production Plant

Figure 9. Machine RCMs for Production Plant

Figure 10. SCMs for Production Plant 
Mean Resource Constraint Metrics for Machines \& Skills (By Shift)

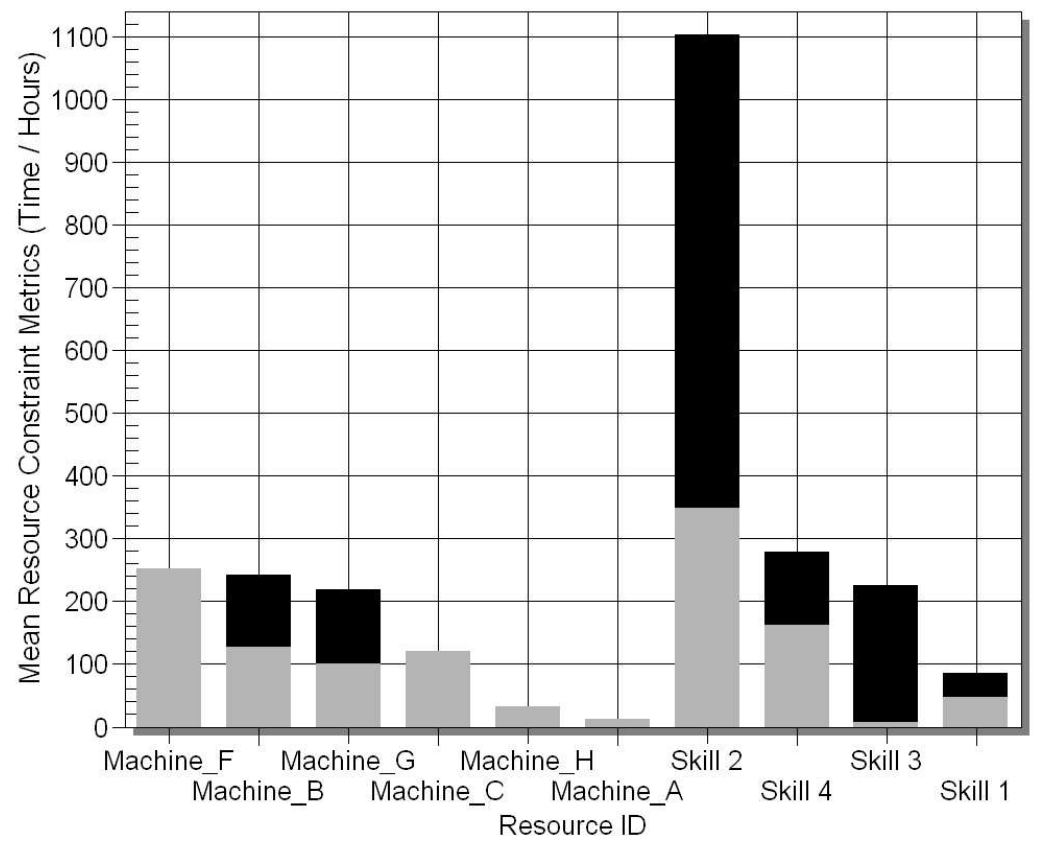

$\square$ Day Shift

Night Shift

$329 \times 235 \mathrm{~mm}(96 \times 96$ DPI $)$ 


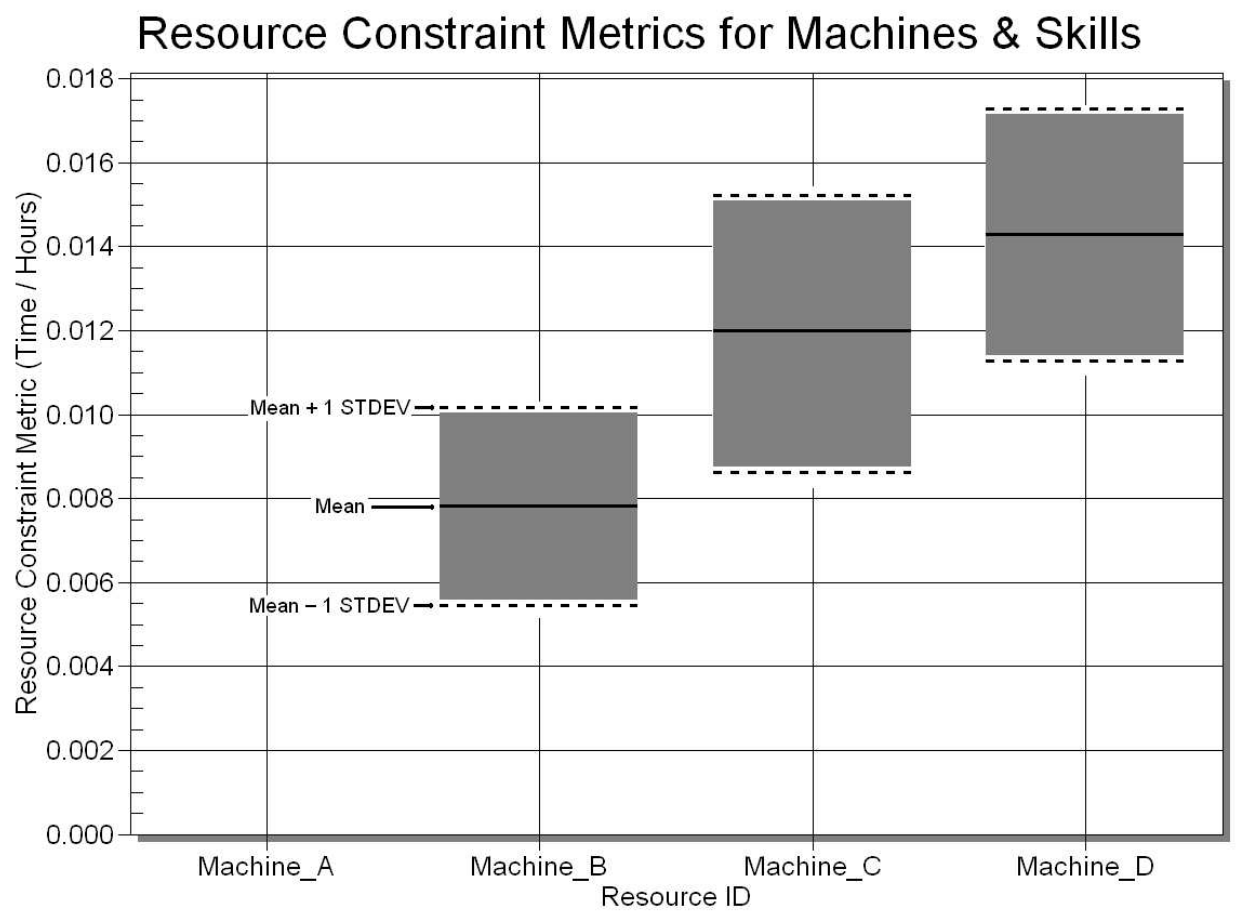

$318 \times 232 \mathrm{~mm}(96 \times 96$ DPI $)$ 


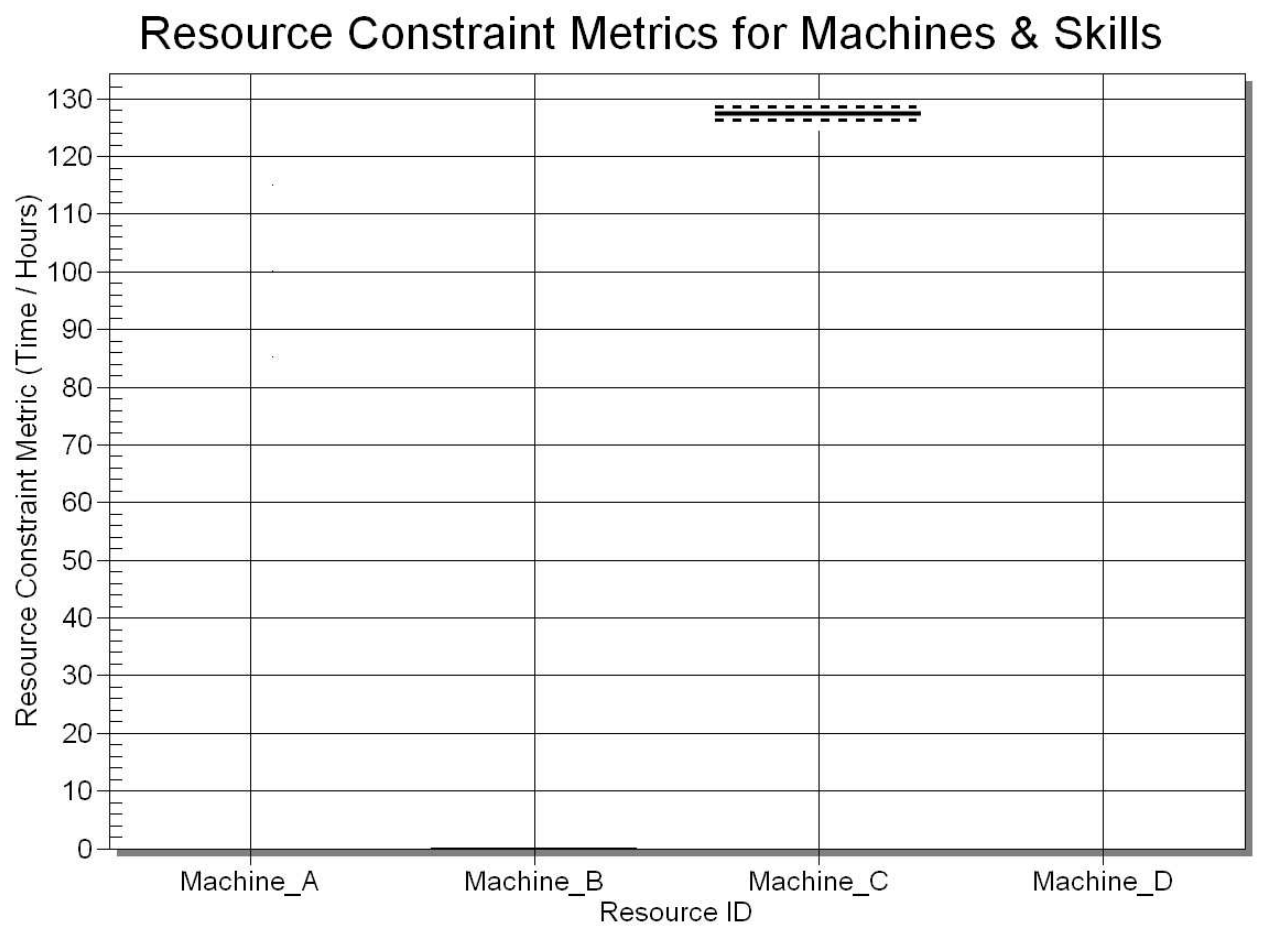

$313 \times 232 \mathrm{~mm}(96 \times 96$ DPI $)$

http://mc.manuscriptcentral.com/tprs Email: ijpr@lboro.ac.uk 


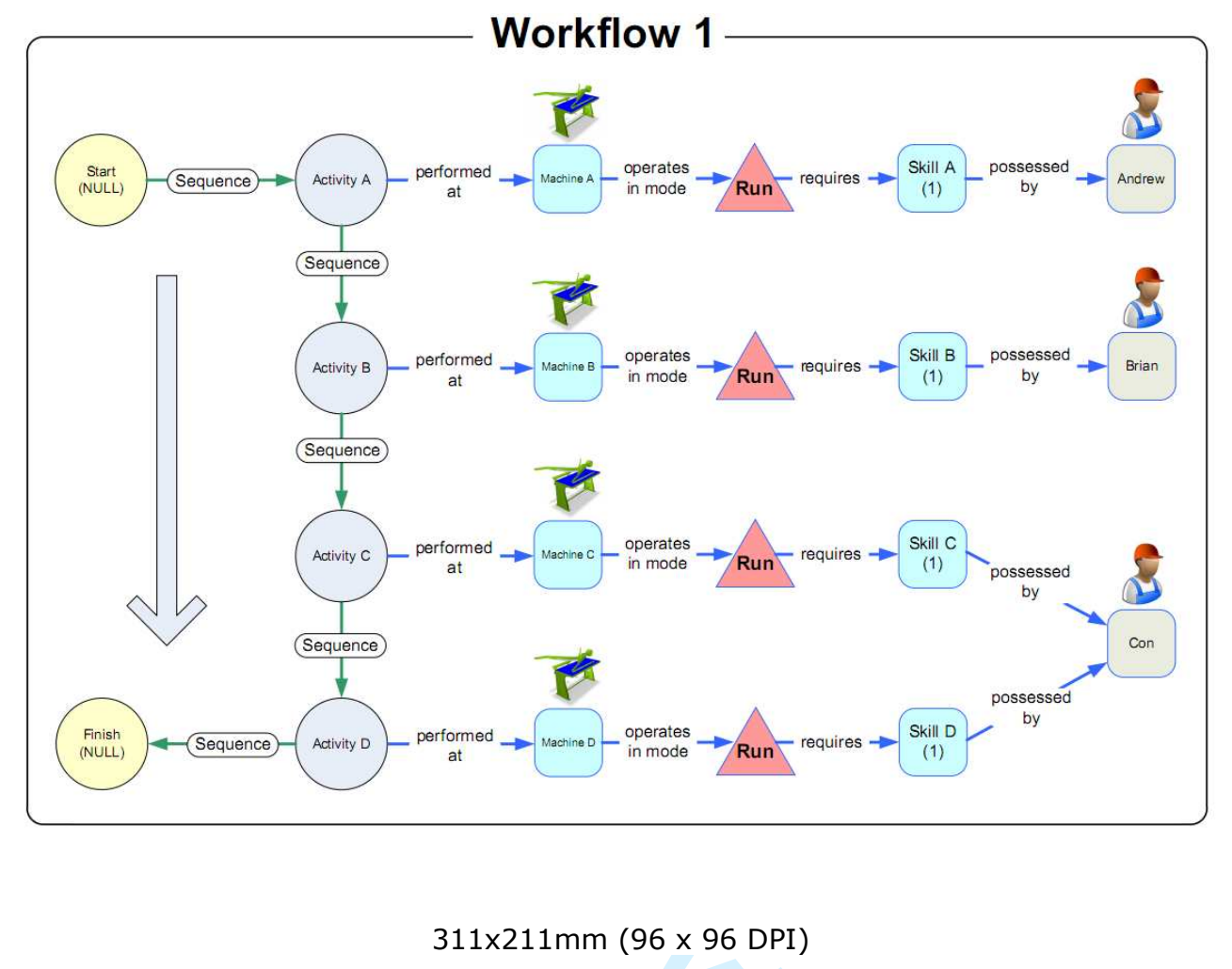

http://mc.manuscriptcentral.com/tprs Email: ijpr@lboro.ac.uk 


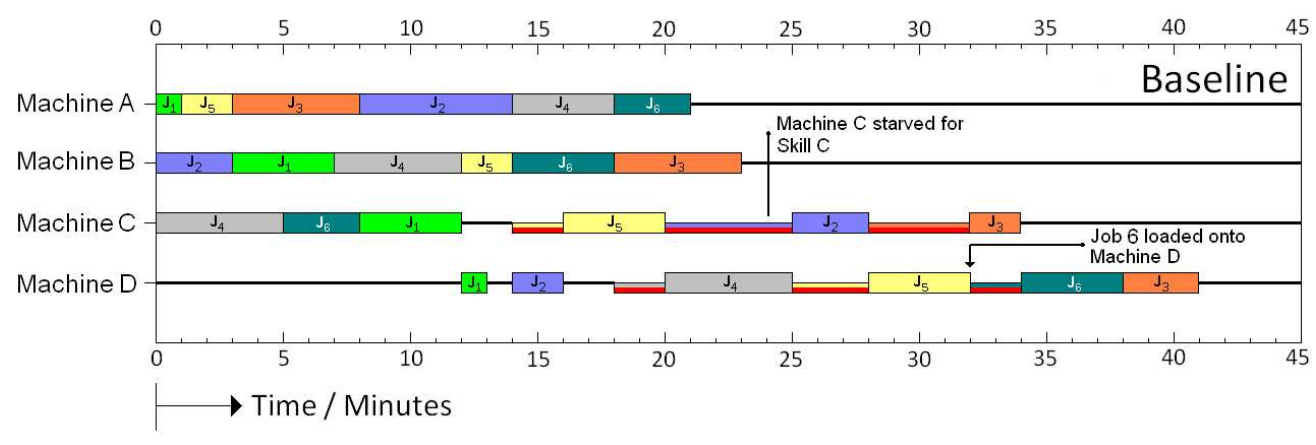

$338 \times 116 \mathrm{~mm}(96 \times 96 \mathrm{DPI})$

http://mc.manuscriptcentral.com/tprs Email: ijpr@lboro.ac.uk 


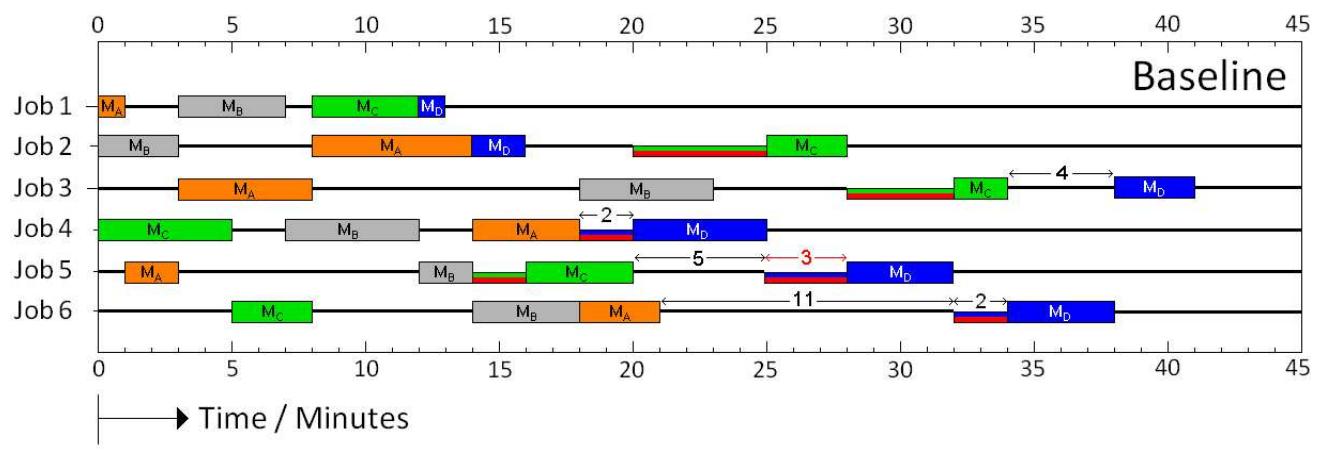

$322 \times 115 \mathrm{~mm}(96 \times 96 \mathrm{DPI})$ 


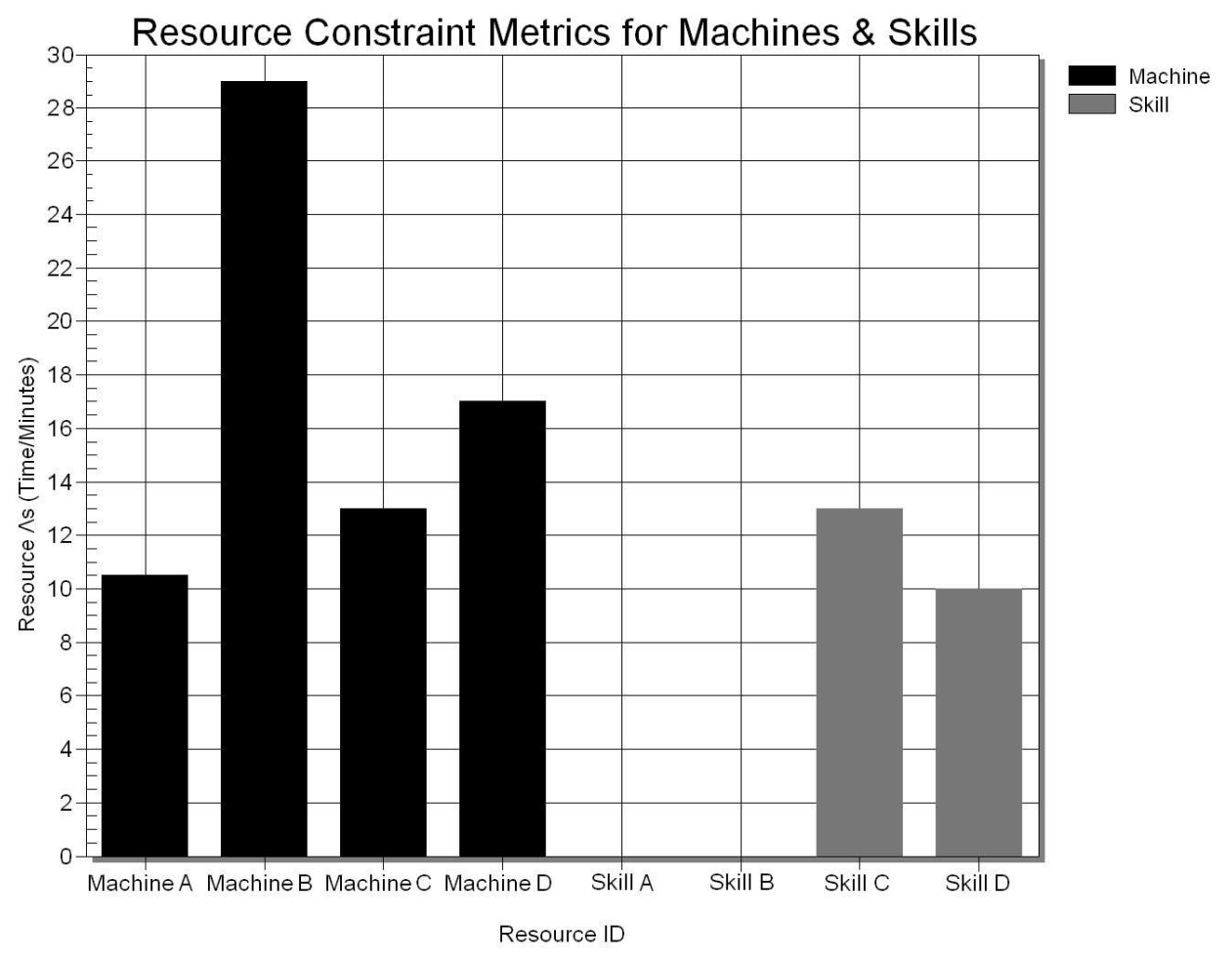

$369 \times 283 \mathrm{~mm}(96 \times 96 \mathrm{DPI})$ 


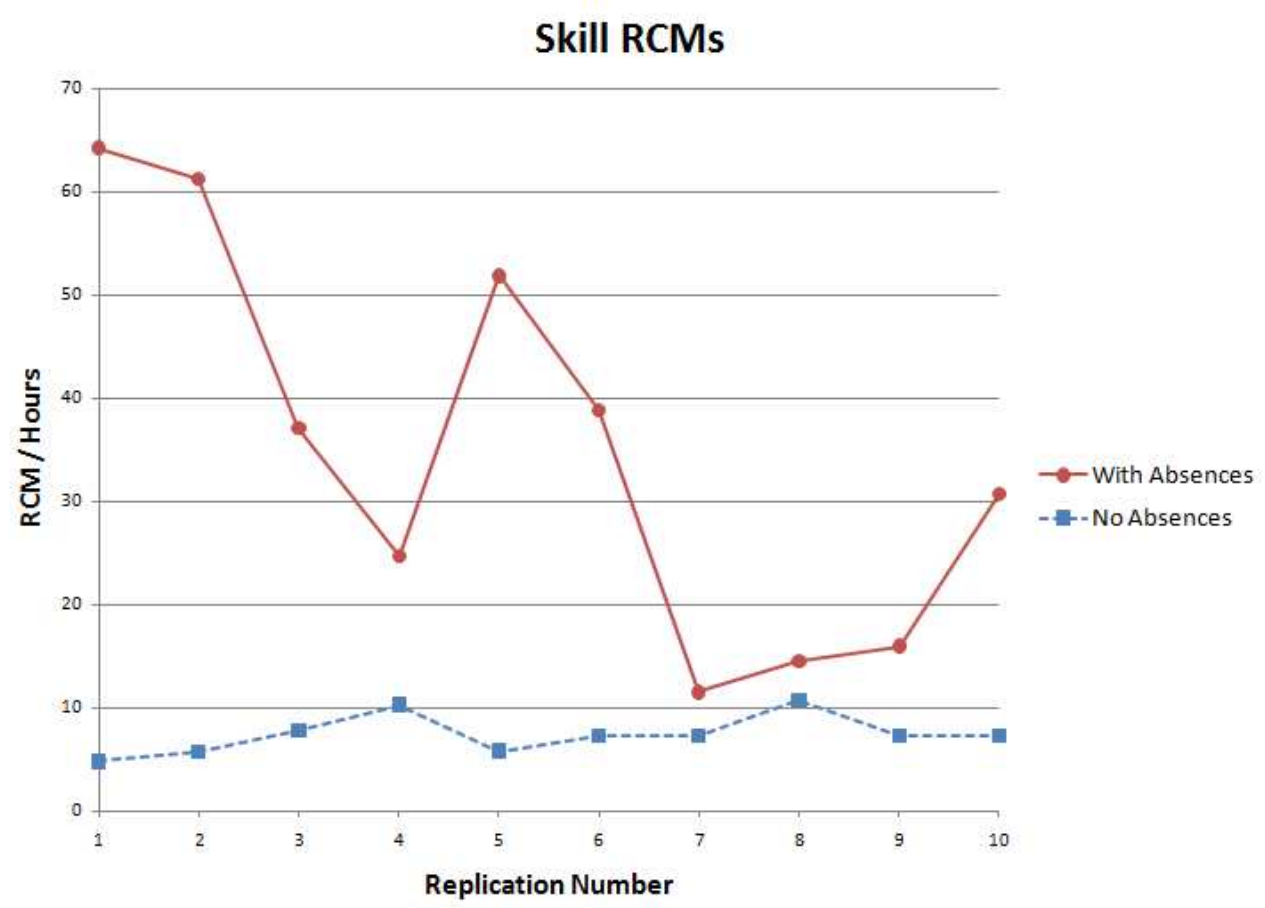

$193 \times 139 \mathrm{~mm}(96 \times 96 \mathrm{DPI})$ 


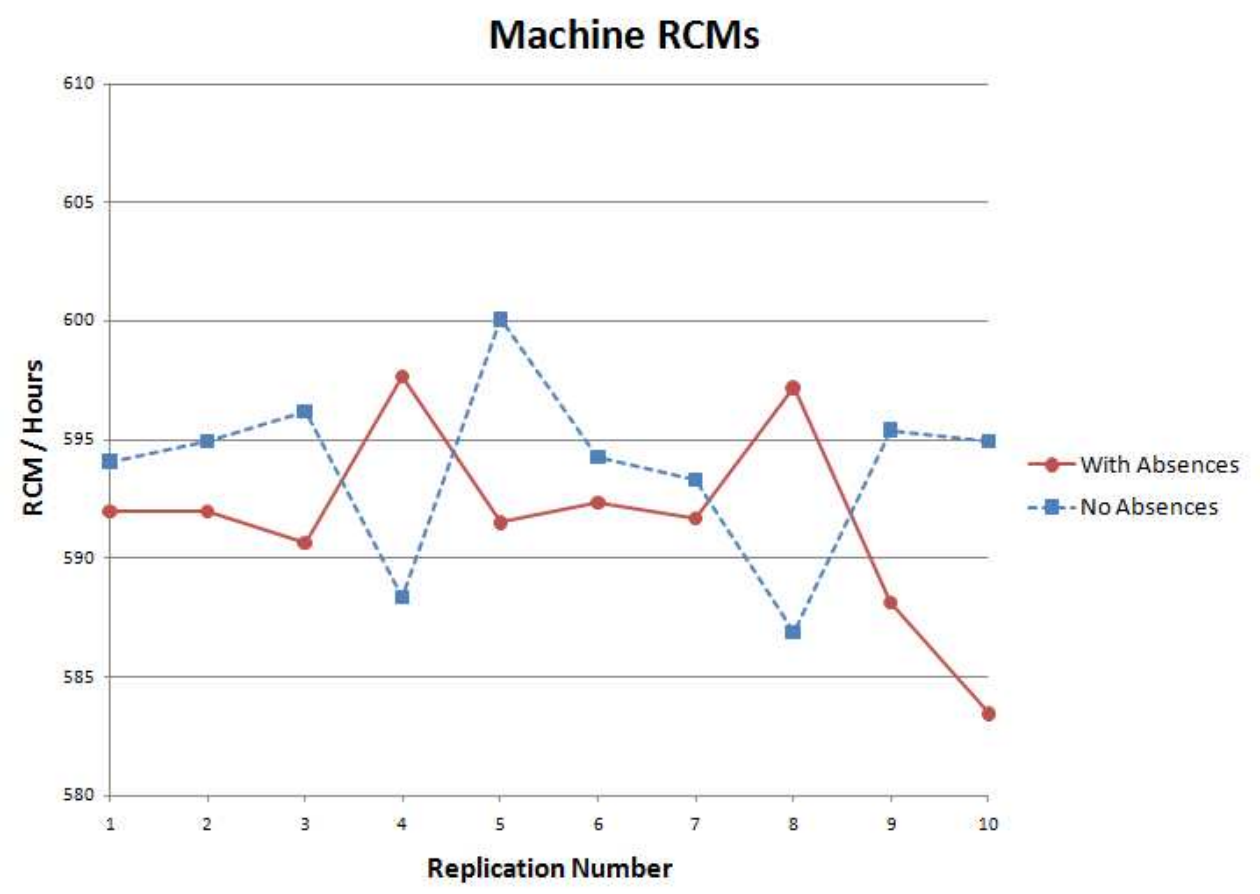

$196 \times 138 \mathrm{~mm}(96 \times 96$ DPI)

http://mc.manuscriptcentral.com/tprs Email: ijpr@lboro.ac.uk 


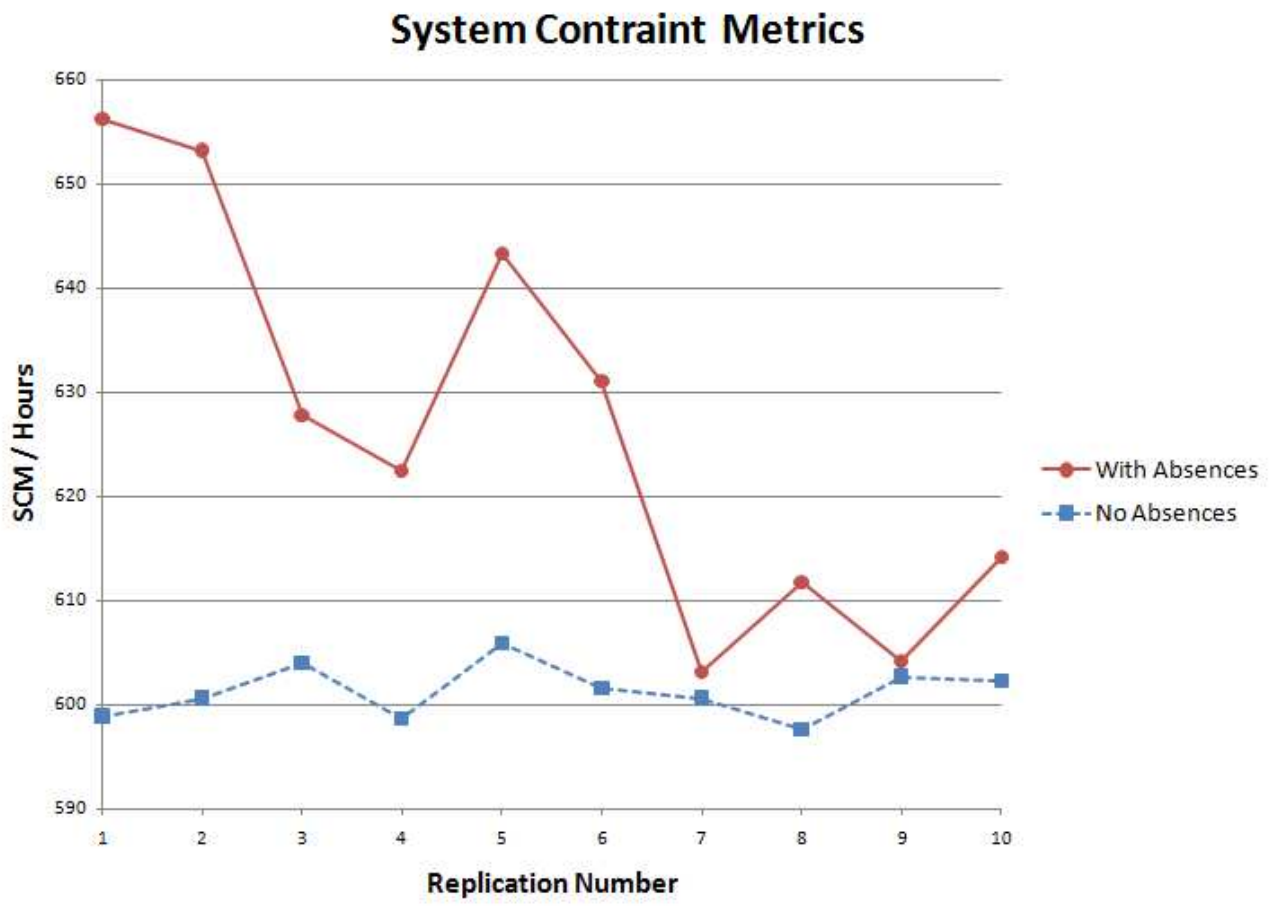

$191 \times 138 \mathrm{~mm}(96 \times 96 \mathrm{DPI})$ 